Advanced copy uploaded online, July 2019. Suggested citation:

Carroll, Megan. Forthcoming. "Asexuality and Its Implications for LGBTQ-Parent Families." In LGBT-Parent Families: Innovations in Research and Implications for Practice [Second Edition], edited by Abbie E. Goldberg and Katherine R. Allen. Springer.

Asexuality and Its Implications for LGBTQ-Parent Families

Megan Carroll, Ph.D.

California State University - San Bernardino

Contact:

Megan Carroll, California State University - San Bernardino, Department of Sociology, 5500

University Parkway SB327, San Bernardino, CA 92407-2397, drmegancarroll@ gmail.com 


\begin{abstract}
Asexuality, most often defined as a lack of sexual attraction, has emerged as a relatively new sexual identity category, and very little research has yet to explore asexual families and parenting. In this chapter, I review the literature on asexuality and its implications for parenting research and LGBTQ-parent families. First, I explain the meanings of asexuality through a review of its competing definitions and the evolving vocabulary of sexual and romantic dispositions within the asexual community. I also examine the methodological issues that have made asexuality especially difficult to research and the growth of asexuality as an identity movement in resistance to pathologizing narratives of sexual dysfunction. Next, I examine intersections between asexuality and gender, race, class, and disability, with critical attention toward the relationship between asexuality and the broader LGBTQ umbrella. I then review existing knowledge of asexual individuals' experiences of parenting, intimate relationships, and marginalization. Practitioners are urged to consider the validity of many types of intimacy as research on asexual parenting can further societal understandings of diverse expressions of love and family formation.
\end{abstract}

Keywords: aromantic, asexual, community, identity, intimacy, marginalization, relationships 
As a marginalized sexual orientation category, asexuality has much to offer discussions of LGBTQ parenting. Asexuality signifies an absence of sexual attraction to people of any gender, challenging dominant paradigms of love, sex, and relationships. Asexual individuals find intimacy and emotional fulfillment through a variety of partnership models, challenging the idea that sexual activity legitimates a relationship or that romantic love should be privileged above platonic love (Scherrer, 2010a). Yet asexualities have long been ignored, to the extent that many continue to associate the "A" in LGBTQIA+ with "ally" rather than "asexual" (Mollet \& Lackman, 2018). Often referred to as "the invisible orientation" (Decker, 2014), asexuality is especially understudied in comparison to other sexual orientations. Yet an understanding of asexuality in the context of LGBTQIA+ family research can help scholars and practitioners adapt to an increasingly diverse, complex, and fluid landscape of gender and sexuality.

This chapter is structured around two key questions: (a) What is asexuality? How is the definition and measurement of asexuality evolving? And (b) What are asexual people's experiences, especially regarding sex, romance, and parenting? How are their experiences characterized by overlapping systems of inequality, especially gender, race, class, and disability? These questions are designed to offer guidance on the intersections of asexuality and LGBTQ parenting and highlight new avenues of research into this understudied topic.

This chapter is informed by theories of intersectionality and postmodernism. Intersectionality theory posits that individual experiences are influenced by multiple axes of one's social location (Collins, 1990). It examines how identity categories and their associated hierarchies interact and create interlocking systems of oppression (Collins, 1990; Crenshaw, 1991; Yuval-Davis, 2006). Many family scholars have been reluctant to incorporate intersectionality as a dominant paradigm, but intersectionality offers a theoretical framework to 
understand how systems of sexuality, gender, race, and other axes of inequality interact and shape family life (Baca Zinn, 2012).

Postmodernism broadly refers to the erosion of shared meanings in society. In the context of families, postmodernism provides a framework for understanding how taken-for-granted associations between marriage, sexuality, and kinship have been challenged by new technologies, demographic changes, and shifting cultural norms (Aveldanes, Pfeffer, \& Augustine, 2018; Stacey, 1996). Whereas sexuality was once more closely associated with one's family life, postmodern sexualities are defined neither by love nor sexual reproduction, allowing eroticism to exist for its own sake (Bauman, 1998). Postmodern concepts of sexuality and family have therefore created the necessary conditions for asexuality to emerge as a self-concept defined by one's distance from eroticism and sexual relationships.

\section{What is Asexuality?}

There is a widespread misconception in society that all humans experience sexual attraction and sexual desire (Carrigan, 2012; Przybylo, 2011). Asexuality is an umbrella term for the identity category that challenges those assumptions. Given the relatively recent emergence of asexuality as a sexual orientation category, the precise definition of asexuality itself remains in flux (Chasin, 2011). The most common definition of asexual—“someone who does not experience sexual attraction"- comes from the Asexual Visibility and Education Network (AVEN), an organization and online resource founded by David Jay in 2001. AVEN has played an important role de-stigmatizing asexuality, and their message boards served as the birthplace of the asexual community by creating a hub for online communication between asexual individuals (Jones, Hayter, \& Jomeen, 2017). AVEN's definition of asexuality appears in much of the literature and is used by many self-identified asexual individuals (Brotto, Knudson, Inskip, 
Rhodes, \& Erskine, 2010; Jones et al., 2017; Van Houdenhove, Gijs, T'Sjoen, \& Enzlin, 2015a). Alternatively, some prefer to describe their asexuality as a lack of interest in sex, not necessarily connected to attraction (Scherrer, 2008). The definition of asexuality is often discussed and contested within online spaces, as not all asexual individuals agree on what "lack of sexual attraction" means (Mitchell \& Hunnicutt, 2019; Scherrer, 2008).

Most research on asexuality uses AVEN's definition, defining asexuality by its relationship to sexual attraction. Van Houdenhove and colleagues (2015a), who studied the interaction between identity, attraction, and behavior among 566 asexual survey respondents aged 18 to 72 , conclude that "lack of sexual attraction" is the most appropriate and most commonly shared definition. A few other studies support the idea that asexuality should be defined by a lack of sexual desire or excitement, rather than attraction (Aicken, Mercer, \& Cassell, 2013; Prause \& Graham, 2007). Behavioral definitions of asexuality are especially rare (see Brotto et al. 2010 for one exception), as asexual discourses actively differentiate asexuality (a sexual orientation) from celibacy (a choice) (Cerankowski \& Milks, 2010). Individuals who experience attraction but choose not to engage in sexual activity, e.g., for religious reasons, would be considered celibate but not asexual (Decker, 2014).

\section{Measuring Asexuality}

Data from a national probability sample in Great Britain suggests that about $1 \%$ of the population is asexual, defined as having no sexual attraction to either men or women (Bogaert, 2004). This number is often used as a benchmark in research on asexualities, though it has been difficult for researchers to replicate. Aicken et al. (2013), also using data from British probability surveys, found that $0.4 \%$ of respondents had never experienced sexual attraction. Nurius (1983), using a sample of 689 undergraduate and graduate students, found that $5 \%$ of men and $10 \%$ of 
women were asexual, defined as those who report not feeling sexual attraction to either men or women.

Methodological limitations in the measurement and identification of sexuality create significant obstacles to gathering data on asexual people as a population. Sexuality is typically measured using criterion of behavior, attraction, and identity that do not translate well for asexualities (Poston \& Baumle, 2010). For example, asexual respondents' sexual behavior tends to vary, making behavior a less reliable metric to identify asexual respondents (Van Houdenhove et al., 2015a). Some researchers may expect asexual respondents to be those who have never had sex (Poston \& Baumle, 2010), but in one study of 79 asexual respondents, $40 \%$ of asexual men and $34 \%$ of asexual women had had sex, with $25 \%$ of men and $19 \%$ of women reporting that they "always enjoyed having sex" (Aicken et al., 2013, p. 121). Behavioral metrics also potentially conflate asexuality and celibacy (Poston \& Baumle, 2010).

Popular instruments of sexual attraction are also unreliable as they tend to measure responses to gendered object of desire, assuming that attraction exists for all respondents equally. For example, the National Survey of Family Growth (NSFG), widely considered to be the most robust and inclusive national survey for measurements of sexuality, asks respondents to decide whether they are (a) only attracted to the opposite sex, (b) mostly attracted to the opposite sex, (c) equally attracted to the opposite sex and the same sex, (d) mostly attracted to the same sex, (e) only attracted to the same sex, or (f) not sure (Poston \& Baumle, 2010). Ostensibly, asexual survey respondents may select "not sure," but the wording of the question is ambiguous and laden with the assumption that all individuals experience sexual attraction (Poston \& Baumle, 2010). 
It is also very rare for asexuality to be included in the identity categories provided on large-scale national surveys. Few people are familiar with the term "asexual" (MacInnis \& Hodson, 2012). Data that has included asexuality as an option has led to significant errors with survey respondents who are ignorant of asexual terminology, creating issues with reliability (M. Hoban, American College Health Association, personal communication, June 19, 2018). More research is needed to identify solutions that would improve reliability of surveys with "asexual" as an identity category option.

\section{Developing an Asexual Vocabulary}

As an umbrella term, "asexual" represents a range of sexual and romantic dispositions that fall outside the norm. Just as binary constructs of gender, sex, and sexuality have been replaced by the understanding that each falls along a spectrum, asexuality is also conceptualized as a spectrum (Decker, 2014). Gendered objects of desire ("male" and "female") at the extremes of more familiar spectrums of sexuality are replaced on the asexual spectrum with the presence of desire itself. In this way, there is a diversity of attitudes toward sex within the asexual community, with some falling closer to one extreme in which they have never experienced sexual attraction and reject the notion of engaging in any sexual activity and others experiencing attraction in very limited circumstances and perhaps even favoring sexual activity in their lives (Carrigan, 2011). Identity categories that have emerged to describe asexual people on the latter end of the spectrum include gray-asexual, in which sexual attraction is experienced rarely or under specific circumstances, and demisexual, in which sexual attraction only occurs after an emotional bond has been formed (Carrigan, 2011; Decker, 2014).

Attitudes toward romance vary significantly among asexual individuals, and the emerging discourse within asexual communities regularly disaggregates sexual and romantic 
attraction (Carrigan, 2011; Jones et al., 2017). This discourse serves to explain that one can be romantically interested in another person and not desire to have sex with them. Just as sexual attraction falls across a spectrum, leading to a proliferation of terms that asexual people use to describe their sexual identities, romantic attraction also occurs along a spectrum. Some asexual individuals are aromantic, meaning they do not experience romantic attraction or have romantic feelings for others, whereas others may strongly desire romantic relationships in their lives (Brotto et al., 2010; Decker, 2014; Van Houdenhove, Gijs, T’Sjoen, \& Enzlin, 2015b).

Within the asexual community, the specific terms for asexual individuals' sexual orientations are regularly combined with terms that describe the individual's romantic orientation (Carrigan, 2011). These romantic orientation identity labels tend to center around gendered object choices, even though sexual activity is ostensibly removed from the equation (Scherrer, 2008). For example, asexual individuals sometimes describe themselves as heteroromantic (romantically attracted to those of a different gender), homoromantic (romantically attracted to those of the same gender), biromantic (romantically attracted to more than one gender), panromantic (romantically attracted to people regardless of gender), and so on (Decker, 2014). When combined with their sexual identity labels, these romantic orientation categories create multi-term identities that asexual individuals may use to describe themselves, such as aromantic gray-asexual, gray-romantic demisexual, or panromantic asexual. This phenomenon is not necessarily limited to asexual individuals. Troia (2018), in her analysis of millennials' sexual identities, found that multi-term identities, non-binary identities, and "asterisk identities" (i.e., qualifying the subjective meanings of identity labels to communicate a more specific understanding of their sexuality; p. 1) were common patterns among young respondents situated within a postmodern era of sexual fluidity. 


\section{Connections to the LGBTQ Community}

Asexuality is one of many sexual identities that has emerged or gained prominence in the postmodern era. Meanings of sexuality have been shifting to accommodate a wider range of perspectives, and people with similar experiences are able to form meaningful connections online, contributing to a growth in (a)sexual identities and communities (Callis, 2014; Carrigan, 2011; Troia, 2018). Carrigan (2011) notes that the asexual community, which primarily manifests in online spaces, has a remarkable ability to create community cohesion while articulating diverse, individual differences surrounding romantic orientations and attitudes toward sex. But integrating asexuality with the broader LGBTQ community has been challenging (Mollet \& Lackman, 2018).

Mollet and Lackman (2018) found that not all self-identified asexual individuals consider themselves to be part of the LGBTQ umbrella, and many have encountered rejection and isolation from within the LGBTQ community (Dawson, Scott, \& McDonnell, 2018; Mollet \& Lackman, 2018). While asexual individuals and LGBTQ individuals share the experience of marginalization within a heterosexist society, some asexual individuals have reported that their ability to "pass" as heterosexual and having an identity defined by a "lack" of something depressed their motivation to participate in collective action (Dawson et al., 2018, p. 387). Some asexual people have found common ground in the LGBTQ community based on their romantic orientations, whereas others feel that being immersed in a sexual community, even an LGBTQ one, is alienating and oppressive (Mollet \& Lackman, 2018). Whether institutional support systems included "asexual" within their LGBTQIA+ lexicon (as opposed to "ally") has also been influential in asexual individuals' sense of belonging (Mollet \& Lackman, 2018; Scherrer, 2008). Further research is needed to investigate how specific shared experiences—such as 
pathologizing, medicalized narratives or mechanisms of discrimination—have created opportunities for community cohesion between asexual individuals and others within the LGBTQIA+ community.

\section{From Pathology to Identity}

Asexuality is not a new phenomenon. The Kinsey Report of 1948 famously created a 7point scale of sexual orientation that described respondents as exclusively heterosexual (0), exclusively homosexual (6), or somewhere in between (Bogaert, 2012). Less widely known is Kinsey's category "X," reserved for those who could not be placed on the Kinsey Scale because they did not experience sexual attraction (Bogaert, 2012; Decker, 2014). The road from Kinsey to the modern asexual identity movement stretches about 50 years, during which time asexuality has been pathologized, dismissed, and invalidated by conventional approaches to human sexuality.

Characteristics of asexuality overlap with ideas about abnormal sexual functioning. Since 1980, the third edition of the Diagnostic and Statistical Manual of Mental Disorders (DSM) has included psychosexual disorders that focus on sexual desire. "Hypoactive sexual desire disorder" (HSDD) is characterized by the DSM as a deficiency or absence of sexual fantasies and desire for sexual activity that causes distress or interpersonal difficulty (Brotto, 2010; Prause \& Graham, 2007). This entry in the $D S M$ has become controversial as it imposes a pathology onto asexual individuals and assumes that "normal" or healthy sexual functioning necessitates sexual desire and sexual fantasies (Flore, 2013; Hinderliter, 2013). Asexual individuals have challenged the idea that they qualify for an HSDD diagnosis, arguing that people with HSDD continue to experience sexual attraction, whereas asexual people do not (Brotto et al., 2010). Researchers have argued that asexual individuals do not meet the DSM's criteria for HSDD because their lack 
of sexual desire does not cause "distress," which asexual discourses also reflect (Bishop, 2013; Hinderliter, 2013). Furthermore, data measuring women's vaginal pulse amplitude (VPA) and self-reported arousal to erotic stimuli has suggested that asexual women have the same capacity for sexual arousal as other women, challenging the idea that asexuality is equivalent to sexual dysfunction (Brotto \& Yule, 2011).

Another pathologizing narrative about asexuality is the misconception that it represents an aversion to sex stemming from exposure to sexual trauma. Research has disputed this assumption, finding that asexual people do not avoid sex due to a fear of sexual activity or forced sexual activity (Brotto et al., 2010; Prause \& Graham, 2007). Rather, asexual people simply have no interest in sexual activity (Brotto et al., 2010). Medicalized, pathologizing narratives that explain non-heterosexualities as either disorders of sexual desire or responses to sexual trauma are not unique to asexuality (Cvetkovich, 2003; Hinderliter, 2013). The history of homosexuality is also strongly characterized by violence under the guise of medicalization, which continues today in the form of conversion therapy (Waidzunas, 2015).

In addition to a history of clinical approaches that have marginalized asexualities, popular assumptions about "human nature" have also pathologized asexuality. Sexual desire is often framed in the public imagination as an innate and universal experience among human beings (Gupta, 2017). As a result, research has shown that asexual individuals—or those who do not experience sexual desire—are viewed as "less human" (MacInnis \& Hodson, 2012, p. 725). As asexual communities have formed and gained visibility, pathologizing narratives about human nature and normal sexual functioning have been publicly challenged (Gressgård, 2013). Asexual people have been careful to distinguish asexuality as a sexual orientation, much like gay, lesbian, and bisexual, each of which describe the orientation of one's sexual attractions (Brotto et al., 
2010; Brotto \& Yule, 2017). In doing so, asexual people are creating a novel identity category and incorporating asexuality as part of a normal spectrum of healthy human sexuality (Foster \& Scherrer, 2014; Gressgård, 2013).

A common theme within asexualities literature is the validation of asexual identities through community engagement (Jones et al., 2017). AVEN and other online communities have made it possible for anyone with an internet connection to find information about asexuality and communicate with asexual-identified people, creating affirming spaces around asexual identities and raising awareness of asexuality (Jones et al., 2017; MacNeela \& McMurphy, 2015). AVEN has been especially instrumental in helping asexual people express themselves and find a sense of belonging given the dearth of representations of asexuality in media (Brotto et al., 2010; Jones et al., 2017). AVEN has also helped social scientists discover and recruit asexual people for research, and some study participants have reported that they only began to identify as asexual once they discovered the language and community surrounding asexuality via the internet and AVEN specifically (Scherrer, 2008). Even the word "asexual" has been inaccessible for many people, leading to moments of personal satisfaction and meaning when respondents discovered it (MacNeela \& Murphy, 2014; Scott, McDonnell, \& Dawson, 2016). Similar experiences of validation have been found in studies of transgender, bisexual, and other populations whose identity labels are rendered invisible within the public sphere (Cashore \& Tuason, 2009; Levitt \& Ippolito, 2014).

Carrigan (2011) describes a pattern among asexual experiences: individuals begin with a feeling of individual difference, which is followed by self-questioning and assumed pathology before arriving at self-clarification and communal identity. In other words, asexual individuals receive the same messages that the rest of society receives about normative sexualities. As they 
discover that they do not fit the normative prescription of wanting sex or experiencing sexual attraction, they begin questioning themselves, seeking explanations for those differences, often arriving at pathologizing conclusions-that is, "something must be wrong with me" (Carrigan, 2011; Van Houdenhove et al., 2015b). Both asexual identity labels and community support, most of which are online and accessible to a wide range of people, serve a function of counteracting those pathologizing narratives and expanding the possibilities of human sexuality, allowing asexual people to understand their feelings and sexual dispositions within a framework that embraces and validates their experience.

\section{What Are Asexual People's Experiences?}

\section{Intersections with Gender, Race, Class, and Disability}

One characteristic of the asexual community that has emerged through small, qualitative samples is its unique gender composition. There have been consistent findings that the asexual spectrum includes more cisgender women than men (Bogaert, 2004; MacNeela \& Murphy, 2014), as well as disproportionate numbers of individuals under the transgender umbrella (Bauer et al., 2018; Van Houdenhove et al., 2015a). Some research suggests that cisgender men may be inhibited from identifying as asexual, noting that there is especially intense social pressure on asexual men (MacNeela \& Murphy, 2014; Przybylo, 2014; Vares, 2018). One respondent, for example, described feelings of being "less of a man because I'm asexual, like it's a weakness or

a failure" (MacNeela \& Murphy, 2014, p. 807). While men may face greater pressure to conform to norms of sexual dominance, theoretical approaches to the intersections of gender and asexuality have also pointed to inequalities in men and women's sexual autonomy, which has granted men more permission to refuse sex and control their own sexual destinies (Fahs, 2010; Gupta, 2018). 
As noted above, disproportionate numbers of asexual individuals exist under the transgender umbrella (Bauer et al., 2018; Van Houdenhove et al., 2015a). The reasons for the overlap between asexualities and transgender embodiments are undertheorized, but the interaction between gender identity and asexuality is a popular topic of discussion within online asexual communities (MacNeela \& Murphy, 2014). While some within the asexual community view their gender and sexual identities as distinct and separate, others described their asexual identities as freeing them from traditional gender expectations (MacNeela \& Murphy, 2014). The gender composition of asexual communities raises many questions within the sociology of sexualities that can help extend theoretical insights into the interaction between gender and sexuality and how cisnormativity and heteronormativity operate to marginalize transgender asexual people (Sumerau, Barbee, Mathers, \& Eaton, 2018).

The race and class dynamics of the asexual community are also undertheorized. Bogaert's (2004) probability sample suggested that asexual people had lower levels of education and socioeconomic status and were less likely to be Caucasian than non-asexual respondents, yet the community that manifests through online forums like AVEN is disproportionately White and college-educated (Bauer et al., 2018). Income and education have been used as control variables in some quantitative studies of asexuality (e.g., Brotto et al., 2010); in turn, much more research is needed that explicitly explores the intersection of socioeconomic status and asexuality. Owen $(2014,2018)$ has analyzed asexuality in the context of racialized sexual scripts that have historically maintained whiteness and white supremacy. For example, Owen (2018, p. 70) writes about the asexual construction of the "mammy" figure, an ideological and political device mapped onto Black bodies that is "undesiring and undesirable," thus representing an overlap between asexuality and Blackness. Additional theoretical approaches that can illuminate the 
relationship between asexuality, race, and class, as well as empirical studies of race and class within the asexual community, are needed.

The literature has also begun to explore intersections of asexuality and disability. Kim (2011) observes that disabled persons are structurally desexualized and stereotyped as asexual, leading to counternarratives from disability social movements that demand sexual rights and perpetuate the idea that sexual desire is universal and innate. At the same time, asexual communities are careful to deny that there is any causal link between asexuality and disability (Cuthbert, 2017). Asexual disabled individuals are then caught between two communitiesdisabled individuals and asexual individuals—-who are actively distancing themselves from each other (Cuthbert, 2017; Kim, 2011). Kim (2011) explains that progressive narratives of disability and asexuality overlap in that both refer to embodiments that do not need to be eliminated or cured.

\section{Parenting}

There has been extremely limited research on asexual parents. One study found that $34 \%$ of asexual men and $21 \%$ of asexual women had children, and similar proportions were married or cohabiting with a partner (Aicken et al., 2013). Yet few researchers have explored more details of asexual parenting. We do not yet know how most asexual individuals come to be parents, or whether the desire to have children varies between romantic and aromantic asexual individuals. It is possible that, like most children raised by LGBTQ parents, most children of asexual parents are born into heterosexual unions (Gates, 2015). But given the variation in sexual behavior among the asexual population, it is also possible that children and families are more easily embraced as consistent with asexual identities. 
Asexuality poses a challenge for our understandings of romantic and sexual relationships, so parenting relationships are a necessary next step for researchers. The lack of research on asexual parenting may be indicative of an infantilization of asexuality, much like the social construction of disability (Kim, 2011). It may also be indicative of a general invisibility and misunderstand of asexuality, especially given how often it is conflated with celibacy (Cerankowski \& Milks, 2010). As researchers continue to investigate details of asexual individuals' intimate relationships, it is important to consider how asexual parenting can also further our understanding of diverse expressions of love and family formation.

\section{Intimate Relationships}

The emerging literature on asexuality has strived to understand the romantic and sexual histories and interests of asexual individuals. For example, some asexual individuals express interest in physical intimacy, like hugging, kissing, or cuddling, as part of their ideal relationship and sufficient for their satisfaction (Scherrer, 2008; Scherrer, 2010b; Van Houdenhove et al., 2015b). Others, especially those identifying as aromantic, describe their ideal relationship as similar to a "close friendship," where emotional intimacy is achieved without any physical intimacy (Scherrer, 2008, p. 629; Van Houdenhove et al., 2015b). Overall, friendship has been identified as a key source of both emotional and physical intimacy for asexual individuals (Dawson, McDonnell, \& Scott, 2016; Scherrer, 2010b). These findings are reminiscent of the "romantic friendships" that characterized Boston Marriages in the late $19^{\text {th }}$ century, which have since been interpreted as lesbian partnerships (Faderman, 1991, p. 18; Rothblum \& Brehony, 1993). Given the large proportions of cisgender women within the asexual community, the sociohistorical connections between Boston Marriages and contemporary constructs of asexuality are worthy of further exploration. 
Some quantitative researchers have identified patterns of romantic and intimate relationships within the asexual population. Brotto et al.'s (2010) sample revealed that $70 \%$ of respondents had been in a romantic relationship at some point in their lives, with $9 \%$ of men and $29 \%$ of women reporting relationships that lasted longer than 5 years. Many asexual people in Brotto et al. (2010)'s qualitative sample craved the intimacy, companionship, and connection that romantic relationships could provide. Although some expressed concern that their asexuality would prevent them from finding meaningful relationships with accepting partners, asexual individuals with romantic interests often find themselves in romantic relationships with nonasexual partners (Van Houdenhove et al., 2015b). In such situations, the type and frequency of sexual activities are often negotiated between partners and vary based on asexual individuals' attitudes toward sexual activity (Brotto et al., 2010; Chasin, 2015; Van Houdenhove et al., 2015b).

The phrase "unwanted but consensual" appears in the literature to describe the sexual encounters that asexual respondents have with their non-asexual partners (Brotto et al., 2010; Prause \& Graham, 2007, p. 346). Sexually active asexual individuals have described their reasons for having sex as a "sacrifice" for the relationship, a way of showing love for their partner, or something that seemed like a normal course for the relationship (Dawson et al., 2016; Van Houdenhove et al., 2015b). Asexual respondents in Brotto et al. (2010)'s study explained that what set them apart from non-asexual people was the lack of excitement or anticipation leading up to sexual experiences. Sex did not help asexual respondents feel closer to their partners, even if it helped their non-asexual partners feel closer to them. Some described needing to focus on something else during sex, which prevented them from creating emotional intimacy (Brotto et al., 2010). 
While some asexual individuals pursue romantic relationships with non-asexual partners, others prefer to stay single—or find similarly asexual partners—rather than make sexual compromises in their relationships (Scherrer, 2010a; Van Houdenhove et al., 2015b; Vares, 2018). Some asexual individuals also report negotiating non-monogamous sexual relationships with their non-asexual partners, often with the condition that their emotional relationship remain closed (Brotto et al., 2010; Copulsky, 2016; Scherrer, 2010b). Asexual people in relationships with another asexual person have described the benefits of not needing to deal with the "messiness" of sexual relationships, expressing appreciation for being able to be naked and physically close to each other without being pressured to have sex (Brotto et al., 2010).

\section{Sexual Activity}

The concept of asexuality has generated much curiosity about asexual individuals' sexual activity and functioning, outside of the context of intimate relationships. Asexual individuals' need for sexual release, specifically their sex drives and experiences of masturbation, are frequent topics of inquiry in the literature. People who identify as asexual can appear in many places along the continuum of experiencing sexual desire (Bogaert, 2004; Brotto et al., 2010). For example, a minority of respondents in Van Houdenhove et al.'s (2015b) study report "normal" libido levels, with one individual expressing annoyance that "that's just my body" (p. 272). Some asexual individuals in Brotto et al.'s (2010, p. 609) study argued that their sexual desire and arousal were not "directed" at anyone because they did not experience sexual attraction.

Attitudes toward sexual activity vary considerably within the asexual community. Some asexual individuals are disgusted by the idea of sex, whereas others are merely disinterested (Van Houdenhove et al., 2015b). Regardless of their level of interest in having sex with other 
people, the literature suggests that masturbation is common among self-identified asexual individuals, including those with lower libido levels (Jones et al., 2017). Brotto et al. (2010) found that a majority of asexual respondents in their quantitative sample masturbated at least once a month. Yet Brotto et al. (2010) also found that when discussing sexual intercourse, masturbation, or their bodies, asexual respondents used language that was less colored by emotion and more focused on the technical language or mechanics of sex. Many described their genitals as "just there," expressing neither disgust nor excitement over genitalia (Brotto et al., 2010). Emotionally-charged language was still used when discussing other aspects of their lives and behaviors, suggesting that their choice of language uniquely reflects respondents' relationship to sex. More research is needed to understand the variation of sexual activity within the asexual community and asexual individuals' engagement with specific practices (such as BDSM) that are coded as sexual (Sloan, 2015; Vares, 2018).

\section{Marginalization}

The emerging literature on asexualities has begun tracing the contours of asexual marginalization. Marginalization emerges in different ways across the life course for asexual individuals, which may have implications for asexual parenting. For example, many report marginalization in the form of feeling different from their peers during adolescence. The emergence of asexual identities has occurred in tandem with the rise in hook-up culture and pervasive sexual content in media and advertising (Przybylo, 2011; Vares, 2018). Many asexual people report that they did not understand "what the fuss was about" and could not relate to their friends' interest in sex (Brotto et al., 2010, p. 610). As asexual individuals age, their alienation from dating networks can turn into alienation from social networks based on parenting and children as their peers create families (MacNeela \& Murphy, 2014). Aromantic asexual 
individuals may be especially alienated from a culture that overwhelmingly portrays individuals without romantic attachments as misanthropic and deeply flawed (MacNeela \& Murphy, 2014).

A common theme within this literature is the denial and dismissal of asexual identities that occurs through interactions with peers, family members, and providers. Asexual respondents report expectations of bias from medical and mental health practitioners, many of whom (perhaps inadvertently) make dismissive or pathologizing comments that fail to affirm their sexual orientation (Chasin, 2015; Foster \& Scherrer, 2014). Pathologizing reactions from family members and others in asexual individuals' personal lives are also common (Mitchell \& Hunnicutt, 2019). In addition to the framing of asexuality as a disorder, whether it be biomedical or a psychological repression of sexual desire, asexual people are often presumed to be immature or just needing to meet the "right person" (MacNeela \& Murphy, 2014). Asexual women are dismissed through gender stereotypes suggesting that women in general are disinterested in sex (MacNeela \& Murphy, 2014). Each of these narratives denies asexuality as a legitimate, meaningful identity category and sexual orientation.

Measuring other forms of harassment and marginalization has been challenging, but in one survey, verbal insults, anti-asexual remarks, and derogatory names were among the most common forms of discrimination reported by asexual individuals, each of which were found to increase stress on respondents (Gazzola \& Morrison, 2012). Sexual violence in the form of corrective rape has also been identified as an experience shared between asexual women, lesbian women, and transgender men, among other gender and sexual minorities (Doan-Minh, 2019). Through these acts of violence, attackers frame their assaults as attempts to "fix" their victims, thus violating both their bodily autonomy and their sexual identity (Doan-Minh, 2019). 
Further research is needed to identify how these forms of marginalization affect asexual parents and their children. It is possible that, like other LGBTQ parents, asexual parents socialize their children to recognize the rich diversity of sexual identities and orientations and actively build resilience for their children through their parenting practices (Bos \& Gartrell, 2010; this volume; Oswald, 2002). But it is also possible that the characteristics of asexuality and asexual discrimination affect children in ways that are unique from other LGBTQ parents.

\section{Implications for LGBTQ-Parent Families}

New paradigms of love and sex emerging from the asexual community have implications for researchers and practitioners working with LGBTQ-parent families. First, asexuality encourages broader recognition of different forms of intimacy (Gressgård, 2013). Asexual individuals find intimacy and emotional fulfillment through friendship, non-sexual romantic partnerships, open and polyamorous relationships, and dyadic, monogamous romantic relationships (Scherrer, 2010a, 2010b). To be more inclusive of asexual parents and families, practitioners must be willing to challenge the idea that sexual activity legitimates a relationship, or that romantic love should be privileged above platonic love (Scherrer, 2010a). Researchers should also consider how the heterogeneity of asexual relationships may shape parenting practices within the asexual community. Much more research is necessary to understand how and why asexual people have children, as well as how those children may be impacted by asexual parents' marginalization.

Practitioners should also be critical of widespread assumptions that sexual or romantic attraction are essential to the human experience (Carrigan, 2012). The same-sex marriage movement has played a role in perpetuating myths of a universal and innate need for sex and romantic love, emphasizing these desires as common to both heterosexual and LGBTQ lives 
(Hinderliter, 2013; Scherrer, 2010a). Research on asexuality suggests that a life well lived need not include sex and romance, and people lacking interest in these dimensions are not deficient or broken in any way (Bishop, 2013; Bogaert, 2012; Gressgård, 2013).

Finally, the process through which asexual individuals negotiate their sexual relationships has implications for people of all sexual orientations (Chasin, 2015). Asexual individuals in relationships with non-asexual partners have found ways to set boundaries, create mutual agreements, and establish consent through open communication with each other (Brotto et al., 2010; Vares, 2018). In doing so, they may be creating new models of mindful, healthy interactions between intimate partners (Chasin, 2015; Scherrer, 2010b).

\section{Directions for Future Research}

The body of knowledge on asexuality is still in its infancy, creating many opportunities for researchers to explore and contribute to a growing field. One major challenge impeding additional research on asexualities is the ability to identify asexual respondents through surveys and qualitative recruitment strategies. Online communities like AVEN are governed by specific norms that may not reflect the experiences of all asexual individuals, yet finding asexual respondents outside of these asexual-specific online spaces is very difficult (Brotto \& Yule, 2009; Chasin, 2011). Methods of recruitment that can triangulate a diverse population of asexual subjects are needed. More research is also needed on how survey instruments can capture asexual respondents when the option "asexual" is sometimes selected erroneously by celibate, non-asexual individuals (M. Hoban, American College Health Association, personal communication, June 19, 2018). It is possible that defining sexual orientation labels on surveys could be helpful, though creating rigid definitions may also have unintended consequences on how different age groups interpret the survey (Williams Institute, 2009). 
More research is also needed to explore intersections of gender, race, and class with asexuality. The data on race within asexual communities has been inconsistent, and few researchers have begun to explore connections between asexuality and racialized sexual stereotypes that might marginalize asexual people of color (Owen, 2014). Higher proportions of cisgender women and transgender individuals within asexual communities also raise more questions than have been answered (Gupta, 2018; MacNeela \& Murphy, 2015; Sumerau et al., 2018). Given the contentious and contradictory relationship that has historically existed between women's sexuality and the feminist movement, asexuality can open new doors to thinking about the relationship between sex and power from a feminist perspective (Cerankowski \& Milks, 2010; Fahs, 2010). The relationship between the rise in online communication and emerging asexual identities also carries important implications for socioeconomic class within the asexual community (Jones et al., 2017; MacNeela \& McMurphy, 2015). At a time when advances in LGBTQ family policy changes disproportionately benefit White, middle class couples, more research is needed to understand how class variation within the asexual community impacts asexual parents (Scherrer, 2010a).

The relationship between asexuality and the larger LGBTQ community is also an area in need of further research. Although Mollet and Lackman (2018) found that asexual-identified people report rejection and isolation from the LGBTQ community, more research is needed to understand points of connection and disruption for asexual and LGBTQ communities and to identify social contexts in which commonalities between asexual and LGBTQ people are most salient. For example, asexual people report experiences of marginalization in the form of discrimination, verbal insults, and pathologizing, medicalizing narratives, all of which are familiar patterns within the LGBTQ community (Gazzola \& Morrison, 2012). Similarly, the 
development of asexual vocabularies and the validation some report after finding the term "asexual" may also be a relevant point of connection (Cashore \& Tuason, 2009; Levitt \& Ippolito, 2014; Scott et al., 2016). More research is also needed to understand the specific sexual practices of asexual individuals and the prominent overlap between asexual and transgender embodiments (Bauer et al., 2018; Sloan, 2015; Van Houdenhove et al., 2015a; Vares, 2018).

Connections between asexuality and the larger LGBTQ community can also shed light on the diverse forms of partnership within the asexual community. Asexual individuals who are in same-sex couples have received extremely limited attention, yet they raise interesting questions about gender and sexuality. For example, findings on asexual men have found that expectations of sexual dominance inhibit men from identifying as asexual (MacNeela \& Murphy, 2015; Przybylo, 2014). How do these identity conflicts extend for asexual men in same-sex relationships, who are stereotyped as especially promiscuous? For asexual women in same-sex relationships, does the history of Boston Marriages provide a framework through which they can interpret their relationship (Faderman, 1991; Rothblum \& Brehony, 1993)? Or do other stereotypes unique to lesbian relationships (e.g., "lesbian bed death") create additional challenges (Nichols, 2004, p. 363)? The vast heterogeneity of romantic and sexual interests within the asexual community creates many opportunities for researchers to explore the diversity of LGBTQ families. 


\section{References}

Aicken, C. R. H., Mercer, C. H., \& Cassell, J. A. (2013). Who reports absence of sexual attraction in Britain? Evidence from national probability surveys. Psychology \& Sexuality, 4, 121-135. doi:10.1080/19419899.2013.774161

Aveldanes, J. M., Pfeffer, C. A., \& Augustine, J. (2018). Postmodern families. Oxford Bibliographies Online. doi:10.1093/obo/9780199756384-0159

Baca Zinn, M. (2012). Patricia Hill Collins: Past and future innovations. Gender \& Society, 26, 28-32. doi:10.1177/0891243211426873

Bauer, C., Miller, T., Ginoza, M., Guo, Y., Youngblom, K., Baba, A., Penten, P., Meinhold, M., Ramaraj, V., Ziebert, J., Trieu, T., \& Adroit, M. (2018). The 2016 Asexual Community Survey summary report. Retrieved from https://asexualcensus.files.wordpress.com/2018/ 11/2016_ace_community_survey_report.pdf. The Asexual Community Survey Team.

Bauman, Z. (1998). On postmodern uses of sex. Theory, Culture \& Society, 15, 19-33. doi:10.1177/0263276498015003002

Bishop, C. (2013). A mystery wrapped in an enigma - asexuality: A virtual discussion. Psychology \& Sexuality, 4, 195-206. doi:10.1080/19419899.2013.774168

Bogaert, A. F. (2004). Asexuality: Prevalence and associated factors in a national probability sample. The Journal of Sex Research, 41, 279-287. doi:10.1080/00224490409552235

Bogaert, A. F. (2012). Understanding asexuality. Plymouth, England: Rowman \& Littlefield. Bos, H., \& Gartrell, N. (2010). Adolescents of the USA National Longitudinal Lesbian Family Study: Can family characteristics counteract the negative effects of stigmatization? Family Process, 49, 559-572. doi:10.1111/j.1545-5300.2010.01340.x 
Brotto, L. A. (2010). The DSM diagnostic criteria for hypoactive sexual desire disorder in women. Archives of Sexual Behavior, 39, 221-239. doi:10.1007/s10508-009-9543-1

Brotto, L. A., Knudson, G., Inskip, J., Rhodes, K., \& Erskine, Y. (2010). Asexuality: A mixedmethods approach. Archives of Sexual Behavior, 39, 599-618. doi:10.1007/s10508-0089434-x

Brotto, L. A., \& Yule, M. A. (2011). Physiological and subjective sexual arousal in selfidentified asexual women. Archives of Sexual Behavior, 40, 699-712. doi:10.1007/s10508-010-9671-7

Brotto, L. A., \& Yule, M. (2017). Asexuality: Sexual orientation, paraphilia, sexual dysfunction, or none of the above? Archives of Sexual Behavior, 46, 619-627. doi:10.1007/s10508016-0802-7

Callis, A. (2014). Bisexual, pansexual, queer: Non-binary identities and the sexual borderlands. Sexualities, 17, 63-80. doi:10.1177/1363460713511094

Carrigan, M. (2011). There's more to life than sex? Difference and commonality within the asexual community. Sexualities, 14, 462-478. doi:10.1177/1363460711406462

Carrigan, M. A. (2012). "How do you know you don't like it if you haven't tried it?" Asexual agency and the sexual assumption. In T. G. Morrison, M. A. Morrison, M. A. Carrigan, \& D. T. McDermott (Eds.), Sexual minority research in the new millennium (pp. 3-20). New York, NY: Nova Science Publishers.

Cashore, C., \& Tuason, M. T. G. (2009). Negotiating the binary: Identity and social justice for bisexual and transgender individuals. Journal of Gay \& Lesbian Social Services, 21, 374401. doi:10.1080/10538720802498405 
Cerankowski, K. J., \& Milks, M. (2010). New orientations: Asexuality and its implications for theory and practice. Feminist Studies, 36, 650-664. Retrieved from http://www.jstor.org/stable/27919126

Chasin, C. D. (2011). Theoretical issues in the study of asexuality. Archives of Sexual Behavior, 40, 713-723. doi:10.1007/s10508-011-9757-x

Chasin, C. D. (2015). Making sense in and of the asexual community: Navigating relationships and identities in a context of resistance. Journal of Community \& Applied Social Psychology, 25, 167-180. doi:10.1002/casp.2203

Collins, P. H. (1990). Black feminist thought: Knowledge, consciousness, and the politics of empowerment. New York, NY: Routledge.

Copulsky, D. (2016). Asexual polyamory: Potential challenges and benefits. Journal of Positive Sexuality, 2, 11-15.

Crenshaw, K. 1991. Mapping the margins: Identity, politics and violence against women of color. Stanford Law Review, 43, 1241-1299. doi:10.2307/1229039

Cuthbert, K. (2017). You have to be normal to be abnormal: An empirically grounded exploration of the intersection of asexuality and disability. Sociology, 51, 241-257. doi: $10.1177 / 0038038515587639$

Cvetkovich, A. (2003). An archive of feelings: Trauma, sexuality, and lesbian public cultures. Durham, NC: Duke University Press.

Dawson, M., McDonnell, L., \& Scott, S. (2016). Negotiating the boundaries of intimacy: The personal lives of asexual people. The Sociological Review, 64, 349-365. doi:10.1111/1467-954X.12362 
Dawson, M., Scott, S., \& McDonnell, L. (2018). “'Asexual' isn't who I am": The politics of asexuality. Sociological Research Online, 23, 374-391. doi:10.1177/1360780418757540

Decker, J. S. (2014). The invisible orientation: An introduction to asexuality. New York, NY: Skyhorse Publishing.

Doan-Minh, S. (2019). Corrective rape: An extreme manifestation of discrimination and the state's complicity in sexual violence. Hastings Women's Law Journal, 30, 167-196. Retrieved from https://repository.uchastings.edu/hwlj/vol30/iss1/8

Faderman, L. (1991). Odd girls and twilight lovers: A history of lesbian life in twentieth-century America. New York, NY: Penguin Books.

Fahs, B. (2010). Radical refusals: On the anarchist politics of women choosing asexuality. Sexualities, 13, 445-461. doi:10.1177/1363460710370650

Flore, J. (2013). HSDD and asexuality: A question of instruments. Psychology \& Sexuality, 4, 152-166. doi:10.1080/19419899.2013.774163

Foster, A. B., \& Scherrer, K. S. (2014). Asexual-identified clients in clinical settings: Implications for culturally competent practice. Psychology of Sexual Orientation and Gender Diversity, 1, 422-430. doi:10.1037/sgd0000058

Gates, G. J. (2015). Marriage and family: LGBT individuals and same-sex couples. The Future of Children, 25, 67-87.

Gazzola, S. B., \& Morrison, M. A. (2012). Asexuality: An emergent sexual orientation. In T. G. Morrison, M. A. Morrison, M. A. Carrigan, \& D. T. McDermott (Eds.), Sexual minority research in the new millennium (pp. 21-44). New York, NY: Nova Science Publishers.

Gressgård, R. (2013). Asexuality: From pathology to identity and beyond. Psychology \& Sexuality, 4, 179-192. doi:10.1080/19419899.2013.774166 
Gupta, K. (2017). “And now I'm just different, but there's nothing actually wrong with me”: Asexual marginalization and resistance. Journal of Homosexuality, 64, 991-1013. doi:10.1080/00918369.2016.1236590

Gupta, K. (2018). Gendering asexuality and asexualizing gender: A qualitative study exploring the intersections between gender and asexuality. Sexualities. Advance online publication. doi:10.1177/1363460718790890

Hinderliter, A. (2013). How is asexuality different from hypoactive sexual desire disorder? Psychology \& Sexuality, 4, 167-178. doi:10.1080/19419899.2013.774165

Jones, C., Hayter, M. \& Jomeen, J. (2017). Understanding asexual identity as a means to facilitate culturally competent care: A systematic literature review. Journal of Clinical Nursing, 26, 3811-3831. doi:10.1111/jocn.13862

Kim, E. (2011). Asexuality in disability narratives. Sexualities, 14, 479-493. doi:10.1177/1363460711406463

Levitt, H. M., \& Ippolito, M. R. (2014). Being transgender: The experience of transgender identity development. Journal of Homosexuality, 61, 1727-1758. doi:10.1080/00918369.2014.951262

MacInnis, C. C., \& Hodson, G. (2012). Intergroup bias toward "Group X": Evidence of prejudice, dehumanization, avoidance, and discrimination against asexuals. Group Processes \& Intergroup Relations, 15, 725-743. doi:10.1177/1368430212442419

MacNeela, P., \& Murphy, A. (2015). Freedom, invisibility, and community: A qualitative study of self-identification with asexuality. Archives of Sexual Behavior, 44, 799-812. doi:10.1007/s10508-014-0458-0 
Mitchell, H., \& Hunnicutt, G. (2019). Challenging accepted scripts of sexual "normality": Asexual narratives of non-normative identity and experience. Sexuality \& Culture, 23, 507-524. doi:10.1007/s12119-018-9567-6

Mollet, A. L., \& Lackman, B. R. (2018). Asexual borderlands: Asexual collegians' reflections on inclusion under the LGBTQ umbrella. Journal of College Student Development, 59, 623628. doi:10.1353/csd.2018.0058

Nichols, M. (2004). Lesbian sexuality/female sexuality: Rethinking ‘lesbian bed death.' Sexual and Relationship Therapy, 19, 363-371. doi:10.1080/14681990412331298036

Nurius, P. S. (1983). Mental health implications of sexual orientation. The Journal of Sex Research 19, 119-136. doi:10.1080/00224498309551174

Oswald, R. F. (2002). Resilience within the family networks of lesbians and gay men: Intentionality and redefinition. Journal of Marriage and Family, 64, 374-383. doi:10.1111/j.1741-3737.2002.00374.x

Owen, I. H. (2014). On the racialization of asexuality. In K. J. Cerankowski \& M. Milks (Eds.), Asexualities: Feminist and queer perspectives (pp. 119-135). New York, NY: Routledge.

Owen, I. H. (2018). Still, nothing: Mammy and black asexual possibility. Feminist Review, 120, 70-84. doi:10.1057/s41305-018-0140-9

Poston, D. L., \& Baumle, A. K. (2010). Patterns of asexuality in the United States. Demographic Research, 23, 509-530. doi:10.4054/DemRes.2010.23.18

Prause, N., \& Graham, C. A. (2007). Asexuality: Classification and characterization. Archives of Sexual Behavior, 36, 341-356. doi:10.1007/s10508-006-9142-3

Przybylo, E. (2011). Crisis and safety: The asexual in sexusociety. Sexualities, 14, 444-461. doi:10.1177/1363460711406461 
Przybylo, E. (2014). Masculine doubt and sexual wonder: Asexually-identified men talk about their (a)sexualities. In K. J. Cerankowski \& M. Milks (Eds.), Asexualities: Feminist and queer perspectives (pp. 225-247). New York, NY: Routledge.

Rothblum, E. D., \& Brehony, K. A. (Eds.). (1993). Boston marriages: Romantic but asexual relationships among contemporary lesbians. Boston, MA: University of Massachusetts Press.

Scherrer, K. S. (2008). Coming to an asexual identity: Negotiating identity, negotiating desire. Sexualities, 11, 621-641. doi:10.1177/1363460708094269

Scherrer, K. S. (2010a). What asexuality contributes to the same-sex marriage discussion. Journal of Gay and Lesbian Social Services, 22, 56-73. doi:10.1080/10538720903332255

Scherrer, K. S. (2010b). Asexual relationships: What does asexuality have to do with polyamory? In M. Barker \& D. Langdridge (Eds.), Understanding non-monogamies (pp. 154-159). London, England: Routledge.

Scott, S., McDonnell, L., \& Dawson, M. (2016). Stories of non-becoming: Non-issues, nonevents and non-identities in asexual lives. Symbolic Interaction, 39, 268-286. doi:10.1002/SYMB.215

Sloan, L. J. (2015). Ace of (BDSM) clubs: Building asexual relationships through BDSM practice. Sexualities, 18, 548-563. doi:10.1177/1363460714550907

Stacey, J. (1996). In the name of the family: Rethinking family values in the postmodern age. Boston, MA: Beacon Press.

Sumerau, J. E., Barbee, H., Mathers, L. A. B., \& Eaton, V. (2018). Exploring the experiences of heterosexual and asexual transgender people. Social Sciences, 7, 162-178. doi:10.3390/socsci7090162 
Troia, B. (2018). "You're the one that put me in a box": Integration, cultural constraints, and fluid LGBTQ+ millennial identities. Paper presented at the $113^{\text {th }}$ Annual Meeting of the American Sociological Association, Philadelphia, PA.

Van Houdenhove, E., Gijs, L., T’Sjoen, G., \& Enzlin, P. (2015a). Asexuality: A multidimensional approach. The Journal of Sex Research, 52, 669-678. doi:10.1080/00224499.2014.898015

Van Houdenhove, E., Gijs, L., T’Sjoen, G., \& Enzlin, P. (2015b). Stories about asexuality: A qualitative study on asexual women. Journal of Sex \& Marital Therapy, 41, 262-281. doi:10.1080/0092623X.2014.889053

Vares, T. (2018). "My [asexuality] is playing hell with my dating life": Romantic identified asexuals negotiate the dating game. Sexualities, 21, 520-536.

doi: $10.1177 / 1363460717716400$

Waidzunas, T. (2015). The straight line: How the fringe science of ex-gay therapy reoriented sexuality. Minneapolis, MN: University of Minnesota Press.

Williams Institute. (2009). Best practices for asking questions about sexual orientation on surveys [Research Report]. Retrieved from http://williamsinstitute.law.ucla.edu/wpcontent/ uploads/SMART-FINAL-Nov-2009.pdf

Yuval-Davis, N. (2006). Intersectionality and feminist politics. European Journal of Women's Studies, 13, 193-209. doi:10.1177/1350506806065752 